American Journal of Applied Sciences 9 (3): 331-336, 2012

ISSN 1546-9239

(C) 2012 Science Publications

\title{
A Unique Novel Approach for Design and Analysis of A Robust Decentralized Self-Tuning Fuzzy PI Controller for a Multi Input Multi Output Process
}

\author{
${ }^{1}$ Sujatha Therese, P. and ${ }^{2}$ N. Kesavan Nair \\ ${ }^{1}$ Department of EEE, Noorul Islam College of Engineering, \\ Kumaracoil TamilNadu, India \\ ${ }^{2}$ Department of EEE,CSI Institute of Technology, Thovalai, TamilNadu, India
}

\begin{abstract}
Problem statement: In the real world most of the controlled processes in industries are Multi-Input Multi-Output (MIMO) in nature.They have more than a single controlled variable that should be manipulated in order to achieve the desired control performance. Approach: Control of non linear Multi Input Multi Output processes, it is a difficult task because of the non stationary behaviour, substantial coupling of multiple variables and severe disturbances. Self tuning fuzzy control is a technique applied to control a MIMO process when the plant parameters are subjected to perturbations and when the dynamics of the systems are too complex for a mathematical model to describe. In this study, a decentralized self tuning fuzzy PI controller is designed for a Multi Input Multi Output Process. Results: The performances of the proposed STFPIC for the MIMO process are compared with fuzzy PI controller under both normal and under $-10 \%$ deviation in time constant in terms of the performance measure Integral Time Absolute Error (ITAE). Conclusion: The proposed STFPIC for the MIMO process shows remarkably improved performance than FPIC.
\end{abstract}

Key words: Fuzzy Logic Controllers (FLC's), Proportional Integral (PI), Membership Functions (MF's), Relative Gain Array (RGA)

\section{INTRODUCTION}

In control Engineering most of the systems are Multi Input Multi Output in nature.In control theory it is certain that MIMO systems will find immediate application in a wide variety of problems (space technology, electrical machines, robotics). The control of MIMO systems is a complicated problem because of the coupling that exists between the control inputs and outputs.When MIMO systems are nonlinear and uncertain their control problem becomes more challenging (Boulkroune et al., 2010).

Decentralised control is a simple approach to control MIMO systems. This method can be used for symmetric systems-Systems with equal number of inputs and outputs (Bobal et al., 2004). Decentralised control technique can also be applied to a wide range of applications from robotics to civil engineering. Approaches to decentralised control differs from one another based on the kind of interaction and model of the system (Keviozky et al., 2006).

PI/PIDcontrollers are widely used in process industries due to the simpliciy of their design and the tuning methods (Mudi and Dey, 2011). PI-FLC's are most common as Proportional (P) and Integral (I) actions are combined in the Proportional Integral (PI) controller which combines the advantages of inherent stability of proportional controller and the offset elimination by integral controller (Mudi and Pal, 2001). Also the performance and tuning of PI controllers for industrial processes is well known among all industrial operators (Kanagaraj et al., 2008). However tuning of PI controller requires an accurate model of a process and effective design rules (Bai et al., 2008).

Now a days fuzzy control has become an alternate to conventional control algorithms to solve problems dealing with complex processes. It combines the advantages of classical controllers and human operators.A suitable choice of control variables plays an important role in fuzzy control design. Typically the inputs to the fuzzy controller are the error (e) and change of error (De). Usually a fuzzy controller is either a PI or PD type depending on the output of the fuzzy control rules. If the output is the change of control signal it is said to be PI type fuzzy control and if the output is the control signal it is said to be PD type fuzzy control (Boubertakh et al., 2010). A fuzzy logic controller is said to be adaptive if any one of its 
tunable parameter changes when the controller is in operation.An adaptive FLC that fine tunes an already working controller by modifying either its SF's or MF's or both of them is called a self tuning fuzzy Logic controller (Hameed et al., 2010). The performance of PI type fuzzy controller for nonlinear and linear processes can be improved by introducing the self tuning mechanism (Arrofiq and Saad, 2008). In STFPIC there are two fuzzy logic blocks one for calculating the gain updating factor and the other for computing the main control (Hameed et al., 2010). In a STFPIC the output scaling factor is adjusted online by a gain updating factor. The value of the gain updating factor'a' is determined from a fuzzy rule base defined on error (e) and change of error (De) of the controlled variable. The proposed self tuning fuzzy controller is designed using a simple rule base and the most natural unbiased MF's (Hameed et al., 2008). The comparative performances of the proposed STFPIC and FPIC are investigated on a heater mixer experimental set up.

In this study, a simple robust decentralised self tuning fuzzy PI controller scheme is adopted for the heater mixer process where the controller gain is adjusted automatically using fuzzy rules. Here, tuning of output SF is considered as the controller gain. Tuning of the output SF has been given the highest priority because of its strong influence on the performance and stability of this system. In this scheme, the FLC is tuned online (while the controller is in operation) by dynamically adjusting its output SF by a gain updating factor ' $a$ '. The gain updating factor is determined from a rule base determined from the knowledge of the system (Mudi and Pal, 1999).

The process discussed here consists of two noninteracting tanks which are heated separately using heating coils. The flow inputs to the tanks are controlled by individual control valves. The controlled variables are the temperatures of both tanks and level of the second tank. The manipulated variables are input to the control valves and heater coils.

\section{MATERIALS AND METHODS}

Experimental setup and model: The heater-mixer setup consists of two non interacting stirred tanks in series as shown in Fig. 1. The contents in the tanks are well stirred by using variable speed agitators. A cold water stream is introduced in the first tank. The content of the first tank is heated using a heating coil. The hot water that over flows the first tank is mixed with water in the second tank. Also cold water stream is introduced in the tank 2. The content of the second tank is heated using another heating coil. The heat inputs to both the tanks can be manipulated continuously using thyristor power control units, which take 4-20 mA as input signals. The cold water inlet flow to both the tanks can be manipulated using pneumatic control valves. The temperatures in the first tank (T1), the second tank (T2) and the liquid level in the second tank (H2) are control variables while the heat inputs to first and second tank (Q1 and Q2) and cold water flow to the second tank (F2) are treated as manipulated inputs. The cold water flow to the first tank (F1) is kept constant and it can be varied by changing the air input to the control valve. The cold water inlet to the first tank (F1) and the cold water temperature (Tc) are treated as measured disturbances (Srinivasarao et al., 2006).

Experimental method is used for obtaining transfer function model around an operating condition. The transfer function model obtained from the process reaction curve method is given below:

$$
\left[\begin{array}{l}
\Delta T_{1}(s) \\
\Delta T_{2}(s) \\
\Delta H_{2}(s)
\end{array}\right]=\left[\begin{array}{ccc}
\frac{2.21 e^{-38 s}}{828 s+1} & 0 & 0 \\
\frac{0.46 e^{-164 s}}{1400 s+1} & \frac{0.96 e^{-88 s}}{1000 s+1} & \frac{-0.14 e^{-132 s}}{900 s+1} \\
0 & 0 & \frac{35.33 e^{-28 s}}{512 s+1}
\end{array}\right]\left[\begin{array}{c}
\Delta Q_{1}(s) \\
\Delta Q_{2}(s) \\
\Delta V_{2}(s)
\end{array}\right]
$$

Design of decentralized controllers: The primary task in the decentralized controller design is to determine the loop configuration, i.e., pairing between the manipulated variable and the controlled variable to achieve the minimum interactions among loops. Usually, Relative Gain Array (RGA) method is used to give a loop pairing criterion (Xiong et al., 2005):

$$
\mathrm{RGA}=\left[\begin{array}{ccc}
0.9998 & 0 & 0 \\
0 & 0.9999 & 0 \\
0 & 0 & 1.0034
\end{array}\right]
$$

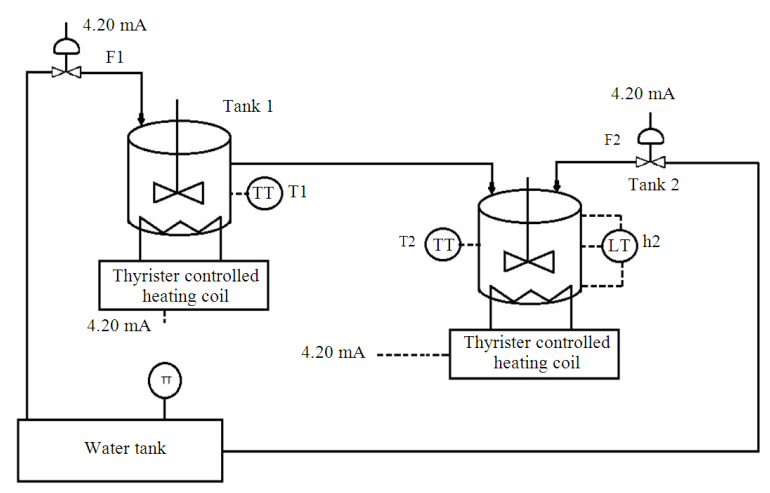

Fig. 1: Experimental setup 


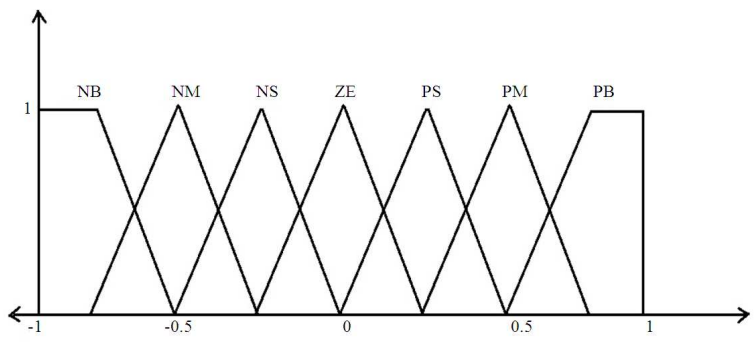

Fig. 2: Membership functions of e, De and Du

\begin{tabular}{llllllll}
\multicolumn{7}{l}{ Table 1: Fuzzy rules for computation of DU } \\
\hline De/e & NB & NM & NS & ZE & PS & PM & PB \\
\hline NB & NB & NB & NB & NM & NS & NS & ZE \\
NM & NB & NM & NM & NM & NS & ZE & PS \\
NS & NB & NM & NS & NS & ZE & PS & PM \\
ZE & NB & NM & NS & ZE & PS & PM & PB \\
PS & NM & NS & ZE & PS & PS & PM & PB \\
PM & NS & ZE & PS & PM & PM & PM & PB \\
PB & ZE & PS & PS & PM & PB & PB & PB \\
\hline
\end{tabular}

In general RGA matrix, element zero indicate that the particular input does not have an effect on the particular output, so temperature (T1) is paired with Q1, temperature (T2) is paired with Q2 and level (H2) is paired with (F2).

Fuzzy PI controller: Fuzzy PI controller generates an incremental control output (Du) from error (e) and change of error (De). The actual value of the controller output (u) is obtained by the accumulation of the incremental change in controller output.

$\mathrm{u}(\mathrm{k})=\mathrm{u}(\mathrm{k}-1)+\mathrm{Du}(\mathrm{k})$

where, $\mathrm{k}$ is the sampling instance.

$\mathrm{Du}(\mathrm{k})$ is the incremental change in controller output. All Membership Functions (MF's) for: 1) controller inputs, i.e., error(e) and change of error(De) and 2) incremental change in controller output( $\mathrm{Du})$ for PI-type FLC are defined in the common interval $[-1,1]$ as shown in Fig. 2. The values of the actual inputs e and De are mapped onto $[-1,1]$ by the input SF's, $G_{e}$ and $\mathrm{G}_{\mathrm{De}}$ respectively.

The controller output $\mathrm{Du}_{\mathrm{N}}$ is mapped onto the respective actual output $\mathrm{Du}$ domain by the output SF $\mathrm{G}_{\mathrm{u}}$. The relationship between the input and output variables of the Fuzzy PI controller are as follows:

$$
\mathrm{e}_{\mathrm{N}}=\mathrm{G}_{\mathrm{e}} \mathrm{e} \quad \mathrm{De}_{\mathrm{N}}=\mathrm{G}_{\mathrm{De}} \text {. De } \quad \mathrm{Du}=\left(\mathrm{G}_{\mathrm{u}}\right) \cdot \mathrm{Du}_{\mathrm{N}}
$$

Selection of suitable values for $G_{e}, G_{D e}$ and $G_{u}$ are made based on the knowledge about the process to be controlled and sometimes through trial and error to achieve the best possible control performance. The incremental change in controller output (Du) for a fuzzy PI controller is determined by rules of the form: If e is $\mathrm{E}$ and De is DE then Du is DU. The rule base for computing Du is shown in Table 1.

The SF's of FLC for a given process has to be tuned to achieve a reasonably good control performance. In doing so, first $G_{e}$ is selected in such a way that the error almost covers the entire domain [-1, 1] to make efficient use of the rule bases. Then $G_{D E}$ and $\mathrm{G}_{\mathrm{u}}$ are tuned to make the transient response of the system as good as possible.

Self-tuning fuzzy PI controller: Self-tuning fuzzy logic controller is applied to heater mixer experimental set up, where the output scaling factor is adjusted online by fuzzy rules according to the current trend of the controlled process. The rule base for tuning the output scaling factor is defined on error (e) and change of error (De) of the controlled variable using the most natural and unbiased membership functions. Block diagram of the proposed self-tuning FLC is shown in Fig. 3.

Membership Functions (MF's) for the gain updating factor ' $a$ ' is defined on $[0,1]$ as shown in Fig. 4, whereas the MF's for controller inputs, error (e) and change of error(De) are same as that of fuzzy PI. For conventional FLC's the controller output $\mathrm{Du}_{\mathrm{N}}$ is mapped onto the respective actual output domain by the output $S F \mathrm{G}_{\mathrm{u}}$. On the other hand, the actual output of the self-tuning FLC is obtained by using the effective $\mathrm{SF}$ ' $\mathrm{aGu}$ ' (as shown in Fig. 3). The incremental change in controller output $(\mathrm{Du})$ is determined by the rules of the form:

\section{If $\mathrm{e}$ is $\mathrm{E}$ and $\mathrm{De}$ is $\mathrm{DE}$ then $\mathrm{Du}$ is $\mathrm{DU}$}

The rule base for computing $\mathrm{Du}$ is shown in Table 1. The tuned scaling factors for fuzzy PI controller are shown in Table 2. The gain updating factor ' $a$ ' is calculated using fuzzy rules of the form:

\section{If $\mathrm{e}$ is $\mathrm{E}$ and $\mathrm{De}$ is $\mathrm{DE}$ then a is $\mathrm{A}$}

The rule base for computing the gain updating factor ' $a$ ' is shown in Table 3. The output-scaling factor $\left(\mathrm{G}_{\mathrm{u}}\right)$ of the STFPIC is taken nearly three times greater than that of FPIC. The value of $\mathrm{G}_{\mathrm{e}}$ and $\mathrm{G}_{\mathrm{De}}$ are kept the same as those of FPIC and ' $a$ ' has to be obtained from the rule base .A large value of $G_{u}$ is permissible due to the factor ' $a$ ' which always lies in the interval $[0,1]$. But such a large value of $G_{u}$ will make either the control performance unacceptable or the system uncontrollable for the conventional FPIC.The tuned scaling factors for self tuning fuzzy PI controller are shown in Table 4. 


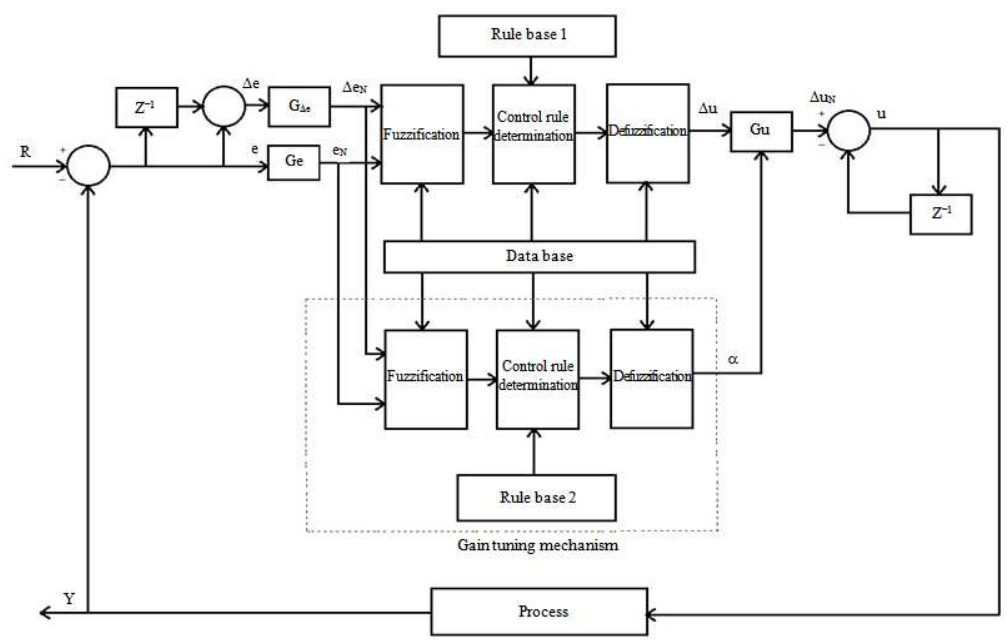

Fig. 3: Block diagram of STFPIC

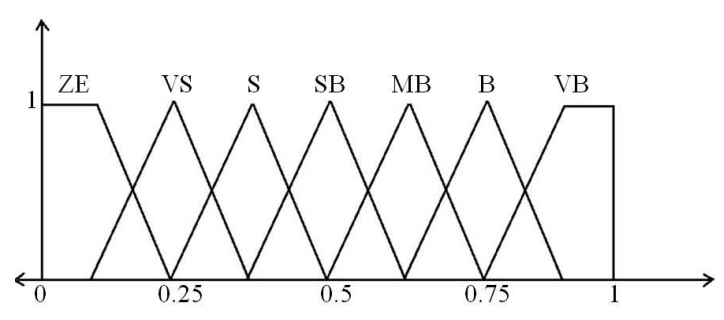

Fig. 4: Membership functions of gain updating factor 'a'

Table 2: Tuned scaling factor for fuzzy PI controller

\begin{tabular}{llll}
\hline & $\mathrm{G}_{\mathrm{e}}$ & $\mathrm{G}_{\mathrm{De}}$ & $\mathrm{G}_{\mathrm{u}}$ \\
\hline $\mathrm{T} 1$ & 0.01 & 12.2 & 0.330 \\
$\mathrm{~T} 2$ & 0.01 & 26.8 & 0.165 \\
$\mathrm{H} 2$ & 0.01 & 9.50 & 0.020 \\
\hline
\end{tabular}

Table 3: Fuzzy rules for computation of gain updating factor ' $a$ '

\begin{tabular}{llllllll}
\hline De/e & NB & NM & NS & ZE & PS & PM & PB \\
\hline NB & VB & VB & VB & B & SB & S & ZE \\
NM & PB & VB & B & B & MB & S & VS \\
NS & VB & MB & B & VB & VS & S & VS \\
ZE & S & SB & MB & ZE & MB & SB & S \\
PS & VS & S & VS & VB & B & MB & VB \\
PM & VS & S & MB & B & B & VB & VB \\
PB & ZE & S & SB & B & VB & VB & VB \\
\hline
\end{tabular}

Table 4: Tuned scaling factor for self tuning fuzzy PI controller

\begin{tabular}{llll}
\hline & $\mathrm{G}_{\mathrm{e}}$ & $\mathrm{G}_{\mathrm{De}}$ & $\mathrm{G}_{\mathrm{u}}$ \\
\hline $\mathrm{T} 1$ & 0.01 & 12.2 & 2.90 \\
$\mathrm{~T} 2$ & 0.01 & 26.8 & 1.60 \\
$\mathrm{H} 2$ & 0.01 & 9.50 & 0.19 \\
\hline
\end{tabular}

\section{RESULTS}

Simulation studies are carried out on the heater mixer process. There are three controlled variables (T1,
$\mathrm{H} 2$ and $\mathrm{T} 2)$ and three manipulated variables (Q1, F2 and Q2) in this process. Figure 5a shows the servo response of $\mathrm{T} 1$ with respect to step change of 1 unit in $\mathrm{T} 1$. Figure $5 \mathrm{~b}$ shows the servo response of $\mathrm{T} 2$ with respect to step change of 1 unit in T2. Fig 5c shows the servo response of $\mathrm{H} 2$ with respect to step change of 1 unit in H2. Figure $6 a$ and $b$ shows the responses of $T 2$ due to interaction with respect to step change of 1 unit in $\mathrm{T} 1$ and $\mathrm{H} 2$ respectively. The performances of the controller under $-10 \%$ deviation in all the time constant parameters is shown in Fig. 7 and 8. Figure 7a shows the servo response of $\mathrm{T} 1$ with respect to step change of 1 unit in T1 under $-10 \%$ perturbation in time constant. Figure $7 \mathrm{~b}$ shows the servo response of $\mathrm{T} 2$ with respect to step change of 1 unit in T2 under $-10 \%$ perturbation in time constant. Figure $7 \mathrm{c}$ shows the servo response of $\mathrm{H} 2$ with respect to step change of 1 unit in $\mathrm{H} 2$ under $10 \%$ perturbation in time constant. Figure $8 \mathrm{a}$ and $\mathrm{b}$ shows the responses of $\mathrm{T} 2$ due to interaction with respect to step change of 1 unit in $\mathrm{T} 1$ and $\mathrm{H} 2$ respectively under $-10 \%$ perturbation in time constant. For quantitative comparison Integral Time Absolute Error is considered as the performance measure. Table 5 shows the ITAE values for servo response and Table 6 shows the ITAE values for sevo response under model uncertainity with $-10 \%$ perturbation in time constant.

Table 5: ITAE values for servo response

\begin{tabular}{llll}
\hline Controller & $\mathrm{T}_{1}$ & $\mathrm{~T}_{2}$ & $\mathrm{H}_{2}$ \\
\hline STFPIC & 80.22 & 335.84 & 57.63 \\
FPIC & 82.49 & 336.14 & 63.50 \\
\hline
\end{tabular}


Am. J. Applied Sci., 9 (3): 331-336, 2012

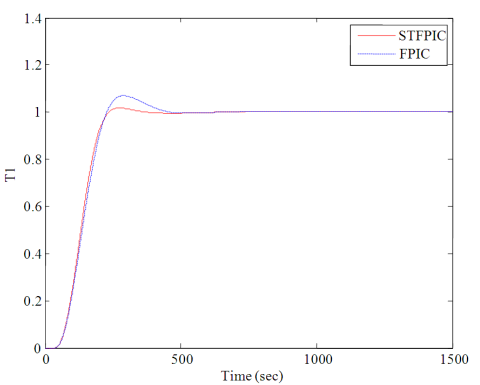

(a)

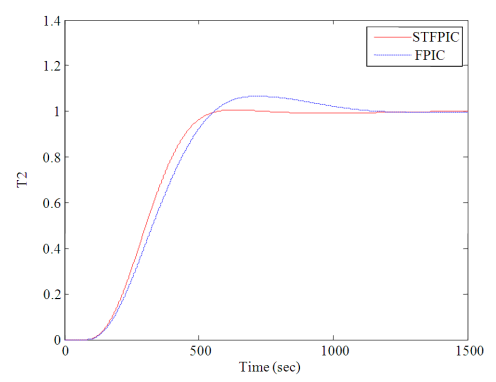

(b)

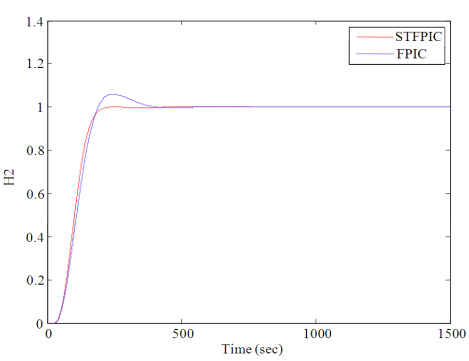

Fig. 5: Servo response of FPI and STFPI controllers

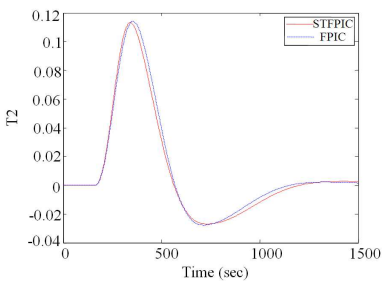

(a)

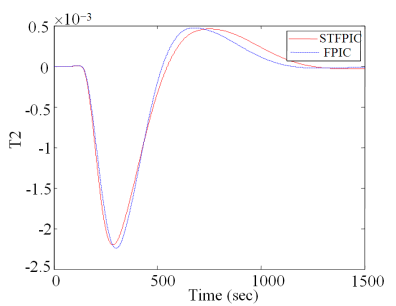

(b)

Fig. 6: Interaction response of FPI and STFPI controllers

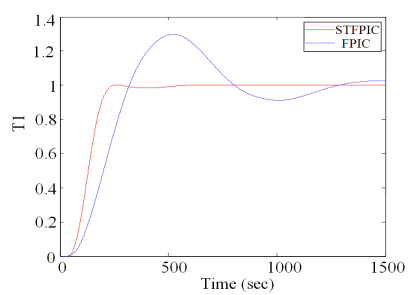

(a)

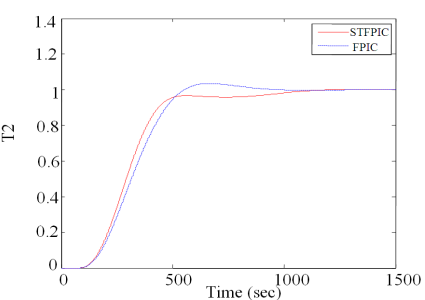

(b)

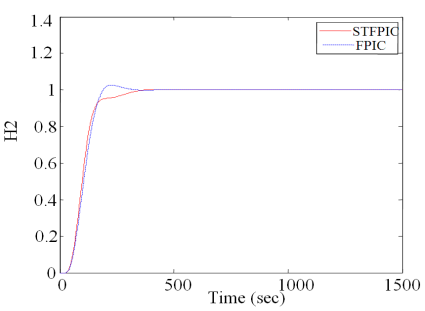

(c)

Fig. 7: Servo response of FPI and STFPI controllers (with $-10 \%$ perturbation in each time constant)

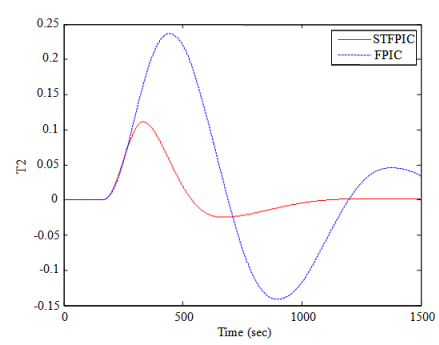

(a)

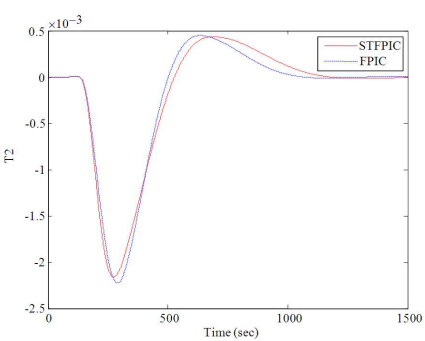

(b)

Fig.8: Interaction response of FPI and STFPI controllers (with $-10 \%$ perturbation in each time constant) 
Am. J. Applied Sci., 9 (3): 331-336, 2012

Table 6: ITAE values for servo response for model uncertainly (with $10 \%$ perturbation in time constant)

\begin{tabular}{lcll}
\hline Controller & $\mathrm{T}_{1}$ & $\mathrm{~T}_{2}$ & $\mathrm{H}_{2}$ \\
\hline STFPIC & 79.09 & 335.72 & 54.46 \\
FPIC & 99.64 & 336.02 & 60.12 \\
\hline
\end{tabular}

\section{DISCUSSION}

The heater mixer experimental set up consists of three controlled variables (the temperature of tank1, $\mathrm{T} 1$, temperature of tank2, T2 and level of tank2, H2) and three manipulated variables(Heat input to tank1, $\mathrm{Q} 1$, Heat input to tank2, Q2 and Flow input to tank 2, F2). Two different types of fuzzy logic controllers are designed for controlling (T1, H2 and T2). One is fuzzy PI and other one is self-tuning fuzzy PI. In fuzzy PI controller the scaling factor remains constant whereas in STFPIC, the scaling factor is tuned on-line by dynamically adjusting its output SF by a gain updating factor ' $a$ '. The controller is tuned separately for three input-output pairs. Using the controller settings given in Table 1 and 2, the performance of the process is evaluated by giving a unit step change in T1, H2 and T2 separately. The Servo and Regulatory responses of the controler are obtained for all the three controlled variables by conducting simulation studies. The servo and regulatory responses obtained reveals that the STFPIC shows remarkably improved performance than FPIC under normal working condition as well as under $-10 \%$ perturbation in time constant. Quantitative comparison is made in terms of the performance measure ITAE.It also reveals that STFPIC gives improved performance than FPIC.

\section{CONCLUSION}

In this study, a fuzzy PI controller and self - tuning fuzzy PI controller are designed for a heater mixer process. The controllers are tuned for three input-output pairs. Performances of self-tuning fuzzy PI controllers were compared with fuzzy PI controllers. ITAE is considered as the performances index. For nominal and robust condition self tuning fuzzy PI controller gives better performance than fuzzy PI controller for the MIMO process. STFPIC shows improved performance in both normal conditions and under-10\% deviation in each time constant.

\section{REFERENCES}

Arrofiq, M. and N. Saad, 2008. A simulation of PLCbased self-tuning PI - fuzzy logic controller for DC motor. Proceedings of the International Symposium on Information Technology, Aug. 2628, IEEE Xplore Press, Kuala Lumpur, Malaysia, pp: 1-8. DOI: 10.1109/ITSIM.2008.4631915
Bai, J., S. Wang and X. Zhang, 2008. Development of an adaptive smith predictor-based self-tuning PI controller for an HVAC system in a test room. Energy Build., 40: 2244-2252. DOI: 10.1016/j.enbuild.2008.07.002

Bobal, V., P. Chalupa and P. Dostal 2004. Application of polynomial methods for design of adaptive decentralized control. Proceedings of the IEEE International Symposium on Computer Aided Control Systems Design, Sept. 4-4, IEEE Xplore Press, Taipei, pp: 115-120. DOI: 10.1109/CACSD.2004.1393860

Boubertakh, H., M. Tadjine, P.Y. Glorennec and S. Labiod, 2010. Tuning fuzzy PD and PI controllers using reinforcement learning. ISA Trans., 49: 543551. PMID: 20605021

Boulkroune, A., M. Tadjine, M.M. Saad and M. Farza 2010. Fuzzy adaptive controller for MIMO nonlinear systems with Known and unknown control direction. Fuzzy Sets Syst., 161: 797-820. DOI: 10.1016/j.fss.2009.04.011

Hameed, S., B. Das and V. Pant, 2008. A self-tuning fuzzy PI controller for TCSC to improve power system stability. Elect. Power Syst. Res., 78: 17261735. DOI: $10.1016 /$ j.epsr.2008.03.005

Hameed, S., B. Das and V. Pant, 2010. Reduced rule base self-tuning fuzzy PI controller for TCSC. Int. J. Elect. Power Energy Syst., 32: 1005-1013. DOI: 10.1016/j.ijepes.2010.02.004

Kanagaraj, N., P. Sivashunmugam and S. Paramasivam, 2008. Fuzzy coordinated PI controller: Application to the real-time pressure control process. Adv. Fuzzy Syst., 8: 1-9. DOI: 10.1155/2008/691808

Keviozky, T., F. Borelli and G.J. Balas, 2006. Decentralized receding horizon control for large scale dynamically decoupled systems. Automatica, 42: 2105-2115. DOI: 10.1016/j.automatica.2006.07.008

Mudi, R.K. and N.R. Pal,1999. A robust self-tuning scheme for PI- and PD-type fuzzy controllers. IEEE Trans. Fuzzy Syst., 7: 2-16. DOI: 10.1109/91.746295

Mudi, R.K. and N.R. Pal, 2001. Anote on fuzzy PI-type controllers with resetting action. Fuzzy Sets Syst., 121: 149-159.

Mudi, R.K. and C. Dey, 2011. Performance improvement of PI controllers through dynamic set-point weighting. ISA Trans., 50: 220-230. DOI: 10.1016/j.isatra.2010.11.006

Srinivasarao, M., S.C. Patwardhan and R.D.Gudi, 2006. From data to nonlinear predictive control. 1. Identification of multivariable nonlinear state observers. Ind. Eng. Chem. Res., 45: 1989-2001. DOI: $10.1021 / \mathrm{ie} 050904 \mathrm{z}$

Xiong, Q., W.J. Cai and M.J. He, 2005. A practical loop pairing criterion for multivariable processes. J. Process Control, 15: 741-747. DOI: 10.1016/j.jprocont.2005.03.008 